\title{
POVOS INDÍGENAS, ESBULHO TERRITORIAL E ANOS DE CHUMBO: LEITURAS DO RELATÓRIO FIGUEIREDO
}

JANE FELIPE BELTRÃ̄ ${ }^{1}$

$U F P A$

PAULO VICTOR NERI CARDEAL ${ }^{2}$

$U F P A$

RESUMO: Povos Indígenas e esbulho territorial, em face da atuação dos agentes do Serviço de Proteção aos Índios (SPI), é a proposta deste artigo. Trabalha-se os anos de chumbo, época da ditadura no Brasil (1964-1985), a partir das leituras do Relatório Figueiredo, considerando as referências relativas à retirada de madeira e arrendamento de territórios indígenas, cujo resultado é a violação dos direitos de etnicamente diferenciados.

PALAVRAS-CHAVE: povos indígenas; ditadura; SPI; Relatório Figueiredo.

ABSTRACT: The present work investigates Indigenous peoples and territorial disseisin in Brazil, facing actions performed by agents of the Indian Protection Service (SPI). We analyze the dark years of the dictatorial period in Brazil (1964-1985), based on readings of the Figueiredo Report, taking into account references regarding the removal of wood and the leasing of Indigenous territories, the result of which is the violation of rights for the ethnically differentiated.

KEYWORDS: Indigenous peoples; dictatorship; SPI; Figueiredo Report.

\section{Etnografia em papeis}

Os papeis etnografados dizem respeito à análise do conjunto documental conhecido como Relatório Figueiredo, encontrado e identificado em 2012, no Museu do Índio, no contexto da Comissão

\footnotetext{
${ }^{1}$ Antropóloga, historiadora, professora titular, docente permanente dos programas de pós-graduação em Antropologia (PPGA) e Direito (PPGD) da Universidade Federal do Pará (UFPA) e docente colaboradora do Programa de Antropologia Social (PPGAS) da Universidade de Mato Grosso do Sul (UFMS). Bolsista de produtividade em pesquisa do Conselho Nacional de Desenvolvimento Científico e Tecnológico (CNPq) nível 1C. E-mail: janebeltrao@gmail.com.

${ }^{2}$ Bolsista de Iniciação Científica - CNPq/UFPA, discente do curso de História da Universidade Federal do Pará (UFPA). E-mail: p_cardeal23@ @otmail.com.
} 
Nacional da Verdade, e que, por muito tempo, foi tomado por perdido em um incêndio ocorrido no Ministério da Agricultura, que destruiu boa parte da documentação do Serviço de Proteção aos Índios (SPI). O Relatório Figueiredo corresponde ao documento conclusivo da Comissão de Inquérito instalada em 1967 pelo gal. Alfonso Albuquerque Lima e presidida pelo procurador Jáder de Figueiredo Côrrea. Comissão que teve por objetivo investigar as irregularidades presentes nas atividades do Serviço de Proteção aos Índios (SPI) - em cinco das nove inspetorias que compunham o órgão à época -, responsável pelas políticas indigenistas no Brasil de 1910 a 1967 e extinto logo após a divulgação do Relatório. ${ }^{3}$

A pertinência das leituras possíveis do Relatório Figueiredo (RF) reside na possibilidade de contar com uma nova fonte para a construção da história indígena no período da ditadura militar, que dá conta da violação dos direitos indígenas especialmente no tocante aos seus territórios.

Discutir-se-á os abusos e as irregularidades dos agentes do Estado para com o patrimônio indígena a partir do arrendamento de seus territórios, à época alvos de grande interesse econômico no que se refere à retirada de madeira e utilização em benefício de terceiros. A ocupação de territórios indígenas produz uma política genocida, marcada pela omissão ou conivência do Estado brasileiro com as negociatas feitas pelos agentes do Estado em nome do SPI.

Entre os papeis compulsados para elaboração da etnografia que apresentamos, manuseamos e lemos com atenção os volumes 7, 8, 9, 10, 11,12 e 13 do Relatório Figueiredo, utilizando como categorias de análise as palavras-chave: arrendamento, madeira e território indígena. $\mathrm{Na}$ perspectiva de cada uma delas, outras palavras chaves foram elencadas para permitir a identificação dos casos de violação. No caso do arrendamento, destacou-se: arrendar, vender (especialmente madeira e gado) e roubar. Para madeira, trabalhou-se com: retirada, derrubada, madeireira, roubo de madeira, queimada, desmatamento e exploração. Em relação ao território Indígena, destacou-se: propriedade, colônia e doação de terras. Os passos foram dados sem que fosse descurado das referências indiretas ao tema, procurando ler as entrelinhas dos contratos

\footnotetext{
${ }^{3}$ Para melhor conhecer o Relatório Figueiredo, consultar Elena Guimarães (2015).
} 
de compra e venda firmados, a existência de recibos frios de prestação de contas de arrendamento, entre outras possibilidades.

O conjunto documental selecionado apresenta denúncias em cada uma de suas folhas. ${ }^{4}$ Assim sendo, buscou-se uma sequência de volumes nos quais a presença do esbulho territorial, produzido pelo arrendamento das terras indígenas e pela retirada de madeira, se fizesse presente de forma intensa, registrando os efeitos sociais que os atos ilícitos produziam aos povos indígenas, remetendo-nos aos demais volumes sempre que a trama histórica exigia.

Procurou-se agir com cuidado em relação aos registros encontrados, especialmente com os casos que ora apareciam como arrendamento, mas na verdade podem ser tomados como apropriação de territórios indígenas. Em virtude da dubiedade dos fatos, tornou-se necessário qualificar e contextualizar os "achados".

\section{Madeira, arrendamento e território indígena registrados}

Em virtude do grande número de registros referentes à madeira, arrendamento e territórios, em cada volume compulsado, fez-se necessário contabilizar ofícios, memorandos, telegramas, ordens de serviço, conclusões, despachos, recibos, que ocupam folhas e folhas do Relatório, selecionando o material de forma a escolher o que se trabalharia. Na sequência, computou-se os contratos de compra e venda, e os editais de concorrência (pública ou administrativa) para venda de madeira, os termos de inquirição e acareação, as atas de reuniões, os testemunhos, as escrituras, entre outros muitos documentos.

Trabalhou-se volume a volume do material selecionado. Entretanto, dada a trama do processo, foi necessário complementar as informações a partir de volumes que referenciam os protagonistas do

\footnotetext{
${ }^{4}$ Tomou-se a termo uma sequência de volumes que correspondem a pouco mais de $20 \%$ do total dos volumes do $R F$. Ousa-se afirmar que em quaisquer dos volumes do conjunto documental há registros que permitem ao/a historiador/a e/ou ao/a antropólogo/a conhecer as histórias de atrocidades do indigenismo praticado no Brasil, pois a cada unidade do SPI "visitada" pelo Procurador, as violações se fazem presentes. Expressão do que se diz é o Volume 1, conhecido como Relatório Síntese do $R F$, cuja leitura é obrigatória. O trabalho ora apresentado compõe os estudos produzidos a partir do projeto: Genocídio \& Povos indígenas. Leituras do Relatório Figueiredo que integra as atividades do Grupo de Pesquisa Cidade, Aldeia \& Patrimônio coordenado por Jane Felipe Beltrão.
} 
caso selecionado. Constatou-se no Volume 7, o primeiro compulsado, que há 18 anotações relativas à madeira, notas sobre 15 arrendamentos e 49 registros sobre terras indígenas, constantes das folhas 1.368 a 1.474 , cuja quase totalidade é composta por imagens relativas à "visitação" do procurador. Ressalte-se que este volume em particular traz a maior quantidade de imagens, as quais merecem estudo à parte, pois há fotografias referentes a momentos do cotidiano nas aldeias, relativas talvez à permanência da Comissão de Inquérito, às quais revelam situações diversas. Entretanto, as imagens terminam sendo meramente ilustrativas, ou pertencem à memória dos membros da referida Comissão, uma vez que não há referências a lugares, à autoria das fotos, e tampouco há legendas.

O Volume 8 que, comprende as folhas de 1.480 a 1.688, é dentre os volumes etnografados o que apresenta maior diversidade de temas relativos à prática do indigenismo, visto que é possível encontrar relatos de abusos sexuais de indígenas mulheres, situações que correspondem à educação indígena, prática de torturas, desvios de verbas públicas, entre tantos outros assuntos. No volume acima referido, há registro de 21 casos de retirada de madeira: 15 relativos a arrendamento e nove envolvendo questões territoriais.

$\mathrm{Na}$ análise do Volume 9, que compreende às folhas 1690 a 2044, encontram-se 49 indicações sobre retirada de madeira; 20 situações de arrendamento e 31 registros sobre territórios indígenas.

O Volume 10, composto a partir das folhas 2.046 a 2.293, apresenta certa predominância das categorias aqui discutidas compreendendo 37 referências à madeira; dez situações de arrendamento e 12 registros sobre terras indígenas. Destacam-se os contratos de compra e venda, em especial aqueles que informam sobre a retirada de madeira.

O Volume 11 , constituído pelo conjunto de folhas de 2.294 a 2.642, apresenta inúmeras prestações de contas referentes aos contratos de compra e venda, estabelecidos a partir das concorrências (públicas ou administrativas) para venda de madeira à $7^{\text {a }}$ Inspetoria Regional. Alguns dos contratos eram firmados por intermédio de pagamentos de prestações que, por vezes, não eram reconhecidas nas contas dos postos indígenas, embora haja recibos de recebimento das quantias devidas 
assinados por agentes do SPI. A quantidade de denúncias provoca a instauração de uma Comissão de Inquérito para apurar as irregularidades constatadas na $7^{\mathrm{a}}$ Inspetoria Regional, considerando o número de situações de arrendamento de terras para retirada de madeira, fato que, em si, compromete a sobrevivência dos povos indígenas.

Os registros referentes à madeira são 24; no que se refere aos arrendamentos, temos cinco anotações; e quatro indicações sobre territórios indígenas.

O Volume 12, compreendendo as folhas 2.644 a 2.871 , apresenta predominância de casos referentes à categoria madeira (62), sobre os quais há recibos de prestação de contas, referências ao código florestal, e aos contratos de compra e venda de madeira.

Por fim, apresentam-se os dados do Volume 13, que abrange as folhas de 2.872 a 3.241. Destaca-se a diversidade de documentos que integram o volume, a saber: termos de inquirição, cartas de acusação, ofícios, ordens de serviço, entre outros. Há uma especificidade referente ao volume: documentos em duplicidade, que são conferidos de maneira "oficial" no Relatório Figueiredo. Contam-se 107 registros sobre madeira; três referências a arrendamentos e 46 anotações sobre terras indígenas.

Concluindo as anotações quantitativas contidas nos volumes examinados, temos o seguinte quadro: 313 indicações referentes à madeira, 74 a respeito de arrendamentos e 151 informam sobre territórios indígenas (Tabela 1).

Relatório Figueiredo

\begin{tabular}{|c|c|c|c|}
\hline Volume & MADEIRA & ARREND AMENTO & TERRIT $\delta R I O$ INDIGENA \\
\hline VII & 18 & 15 & 49 \\
\hline VIII & 16 & 21 & ๆ \\
\hline IX & 49 & 20 & 31 \\
\hline$x$ & 37 & 20 & 12 \\
\hline$x I$ & 24 & 5 & 4 \\
\hline XII & b2 & - & - \\
\hline XIII & $10 ?$ & 3 & 46 \\
\hline Total & 31,3 & 74 & 151 \\
\hline
\end{tabular}

Folhas: De 1368 a 3241 
Os volumes analisados correspondem a pouco mais de $20 \%$ do Relatório Figueiredo, e à análise de pouco mais de 2.000 folhas, das 7.000 que compõem o conjunto documental, o que nos permite inferir, pela amostra, que as ilações madeira/arrendamento/território indígena são pertinentes e trazem a lume um cenário de esbulho e violação de direitos indígena, produzindo deslocamentos forçados, redução de territórios e dificuldades relativas à escassez das áreas destinadas à caça, à pesca e à agricultura, efeitos sociais de alta gravidade que comprometem a vida cotidiana de inúmeros povos indígenas.

\section{Um caso emblemático: a Ajudância do Xingu (Altamira-Pará)}

A leitura dos volumes do Relatório Figueiredo, anteriormente relacionados, tornou evidente as dificuldades impostas aos povos indígenas em função do arrendamento de suas terras a terceiros pelo Serviço de Proteção aos Índios (SPI), para retirada de madeira e outros produtos. O caso referido aqui como Ajudância do Xingu (Altamira, Pará) é emblemático, considerando primeiramente o envolvimento de sertanistas bastante conhecidos na história recente do indigenismo no Brasil, no caso, Francisco Furtado Soares de Meireles (Inspetor de Índios P. 1801 - 14.B do SPI) e José Marinho Teles Filho (Telegrafista CT. 207.12A do órgão), respectivamente, chefe e chefe substituto da 2a Inspetoria Regional do SPI, em Belém (PA). Em segundo lugar, pelo conflito instaurado entre a Ajudância do SPI no Xingu e a Prefeitura do município de Altamira, em face de interesses divergentes que criou embaraços com o executivo e o judiciário, de desastrosa repercussão. Em terceiro plano, considerou-se os protagonistas indígenas, envolvidos nas tramas de arrendamento e retirada de madeira e outros produtos, a saber: os Gaviões de Oeste, que hoje se autodenominam Parkatêjê, Kyikatêjê e Amikratêjê, correspondente ao atendimento do Posto de Atração ${ }^{5}$

\footnotetext{
${ }^{5}$ A prática da atração integra o conjunto de ações relativas à pacificação dos povos indígenas. A prática consistia em preparar uma expedição para "convencer" os povos indígenas isolados, supostamente sem contato com os não indígenas, a integrarem um posto de atração, ou seja a permanecerem em um determinado espaço, o que liberava o restante do território para empreendimentos. Os povos indígenas alvo das práticas de atração são conhecidos hoje como em isolamento voluntário. Sobre o assunto. consultar Peter Gow (2011), Antônio Carlos de Souza Lima (1995) e Rubens Valente (2017), para compreender tanto
} 
denominado Mãe Maria, hoje, Reserva Indígena Mãe Maria; e os Kayapó da área correspondente ao Posto Indígena Gorotire - fatos que ainda hoje consomem os povos indígenas supramencionados. Afora o fato de ser uma das poucas ações registradas na Amazônia nas folhas do Relatório Figueiredo, abrangendo uma grande proporção de territórios indígenas no Pará e não apenas o Rio Xingu, pois alcança o Araguaia Tocantins, fato que dificulta o gerenciamento e a proteção da área sob jurisdição da Ajudância. ${ }^{6}$

Inicia-se a análise pela denúncia feita pelo então vice-prefeito de Altamira (PA), sr. José Batista da Silva, em documento datado de 15 de setembro de 1967, dirigido ao general interventor do Serviço de Proteção aos Índios, do Ministério do Interior e Justiça, em Brasilia (DF). Diz o gestor municipal:

[N]a qualidade de Vice-Prefeito deste Municipio, peço vênia a Va. Excia., para estender a vossa intervenção até ajudancia do serviço neste Municipio de Altamira, seus cinco postos instalados em vários pontos desta imensa região, afim afim de verificar in-lo-co as gritantes irregularidades verificada nos referidos Postos.

Por incrivel que pareça na sede a Ajudancia, d'esse Serviço, n'esta cidade, é a onde funciona e está instalado o comercio de compra e venda de todas as operações de gêneros de industria extrativa, que em maior parte é adquirido pelos selvícolas e totalmente despachados em nome do S.P.I., para se furtarem ao pagamento dos impostos Municipais e Estadual, que goza o referido SERVIÇO. Sendo somente o que se oferece para 0 presente (RF, vol. 8, p. 1.492 , sic).

Observa-se pelo registro que há disputa entre a Prefeitura de Altamira e o SPI, aparentemente motivada pelo fato de que as compras feitas pelo órgão são isentas de impostos. O gestor não parece compreender, ou finge não compreender, que os bens são adquiridos pelo SPI para os povos indígenas da região do Xingu. O gestor parece desejar aumentar a receita do município, incluindo as pessoas indígenas

as nuances da ação, como também a "aura" de heroísmo que animava os sertanistas, em que pese o perigo que enfrentavam.

${ }^{6}$ Para se ter uma ideia das dificuldades de alcançar a área do Araguaia Tocantins, à época, saía-se de Belém para Marabá, e de Marabá até a Aldeia do 30; eram vários dias de viagem em lombo de burro, como contam Roque de Barros Laraia e Roberto DaMatta (1967) em Índios e Castanheiros: a empresa extrativa e os índios do Médio Tocantins. 
como contribuintes. Ou ainda, veladamente indica que as compras não necessariamente são feitas para pessoas indígenas, mas para os funcionários do SPI. Entretanto, não se descarta a possibilidade de outras motivações servirem como pano de fundo à denúncia que, antes de tudo, expressa o conflito aberto Prefeitura versus Ajudância.

Em 27 de setembro de 1967, o fato gerou um documento assinado

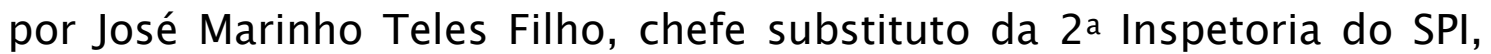
sediada em Belém, a enviado ao presidente da Comissão de Inquérito, Jader de Figueiredo Correia, no qual Marinho se defende das insinuações que pesam sobre os agentes do SPI (RF, v. 8, p. 1.494).

Marinho anexa ao M/M no 195/67 antes referido um documento reservado, que responde aludindo ao telegrama (registrado no RF sob o $\mathrm{n}^{\circ}$ 212, datado de $1^{\circ}$ de setembro de 1967), enviado por Jader de Figueiredo à chefia da $2^{\text {a }}$ Inspetoria Regional, dirigida por Francisco Furtado Soares de Meireles. Na introdução do longo documento de caráter reservado, diz Marinho que se dirige àquela autoridade porque a chefia da unidade encontrava-se "em serviço de pacificação na região do Xingu e considerando ainda que a sua ausência será bastante demorada, peço vênia para prestar os esclarecimentos exigidos por Vossa Senhoria" (RF, v. 8, p. 1.495).

Marinho procura explicar, ponto a ponto as questões postas pelo procurador, começando pela "extração de madeira na região do Tocantins, ou mais precisamente, na área do Posto Indígena 'Mãe Maria'" (RF, v. 8, p. 1.495), afirmando

que realmente existe um contrato entre esta Inspetoria Regional e o Sr. Wladirson O. Penna, devidamente registrado em Cartório e do conhecimento do Sr. Cel. Hamilton de Oliveira Castro, ex-Diretor do SPI, visto que Ihe foi dado a conhecer quando da sua passagem por esta Capital, além da troca de expediêntes sôbre o assunto, mantida entre esta Regional e a Diretoria. O contrato não se restringe únicamente a extração de mogno, mas sim, a toda espécie de madeira leve, com densidade inferior a 0,900 ks. Das duas mil (2.000) árvores constantes de contrato, apenas duzentas e cincoenta (250) foram abatidas e que corresponde a 
quinhentas (500) toras, aproximadamente (RF, v. 8, p. $1.495, \mathrm{sic}) .^{7}$

Esclarece ainda que o referido contrato "tem vigência de dezoito (18) meses e está prestes a extinguir-se, visto que foi assinado em 5 de julho de 1966, não havendo mais, portanto, condições para novas derrubadas". Na tentativa de não deixar dúvidas, informa que

\begin{abstract}
nos últimos dias do mês de maio [1967] empreendí inspeção ao Posto "Mãe Maria", ocasião que colhí detalhes sobre o andamento dos trabalhos, podendo vos assegurar que até aquela data nenhuma tora de madeira havia sido retirada, isto é, permaneciam nos igarapés (RF, v. 8, p. 1.495 , sic).
\end{abstract}

Prossegue afirmando que "pessoas habituadas àquele serviço" teriam informado que as toras de madeira "não seriam retiradas, em virtude das águas já estarem bastante baixas". E encerra as afirmações dizendo que "[a]ssim sendo, acredito que as madeiras extraídas, ainda permaneçam nos igarapés, aguardando a próxima enchente" (RF, v. 8, p. 1.495).

Ao falar de sua possível participação no arrendamento das terras, disse o seguinte:

Apenas exercí vigilância quando do início dos trabalhos, a fim de evitar que elementos perniciosos se infiltrassem na área indígena. Posso assegurar a Vossa Senhoria que não há e nunca houve, pelo menos durante a presente gestão, exportação de mogno ou de outra qualquer espécie de madeira, por parte desta Inspetoria Regional; o que existe de verdadeiro, é o que acima ficou exposto, um contrato honesto, criterioso e devidamente autorizado pela direção do S.P.I. (RF, v. 8, p. 1.4951.496, sic).

E tenta concluir o assunto, afirmando:

[A]pós noventa (90) dias da assinatura do contrato, esta Chefía recebeu DOIS MIL E OITOCENTOS CRUZEIROS

\footnotetext{
${ }^{7} \mathrm{O}$ contrato de arrendamento é encontrado sob o número 24 , em anexo ao documento de defesa de José Marinho Teles Filho que integra o Volume 28 (p. 6.523, anverso, e 6.524, anverso e verso) do Relatório Figueiredo. No contrato, Marinho é testemunha, juntamente com Wilson Souza, da assinatura do mesmo por Francisco Meireles. A defesa de Marinho se estende das folhas 6.493 a 6.528. Todos os documentos da defesa são autenticados por cartórios situados em Belém, entre eles: Chermont, Diniz e Queiroz Santos.
} 
NOVOS - $($ Ncr\$- $2.800,00)$ referentes a VINTE POR CENTO $(20 \%)$ do total de QUATORZE MIL CRUZEIROS NOVOS - (Ncr\$-14.000,00), correspondentes a duas mil (2000) árvores a SETE CRUZEIROS NOVOS - (Ncr\$7.00), por árvore abatida. A importância recebida destinou-se a vários pagamentos atrasados, conforme comprovantes em nosso poder (RF, v. 8, p. 1.496, sic).

Sobre a venda de "castanha-do-Pará" (duzentas caixas contendo 75 hectolitros do produto) que gerou conflito em Altamira, diz que

houve realmente ação judicial movida por esta Regional contra a firma A. C. Maués, estabelecida na cidade de Altamira. A referida firma adquiriu o produto de um comerciante ambulante, conhecido como "regatão", que operava na região do rio Frêsco, afluente do Xingu, local onde está situado o Posto Indígena Gorotire, sem que o responsavel pela Unidade, comunicasse à Chefía da Inspetoria a ocorrência (RF, v. 8 , p. 1.496 , sic).

Entretanto, alega em sua defesa que,

em virtude de naquela época encontrar-me na cidade de Altamira, para onde me havia deslocado a serviço, chegou ao meu conhecimento, através de pessoas que retornavam dos altos rios, ter havido aquela compra indevida. Imediatamente oficiei ao Sr. Suplente de Juiz de Direito - rábula- e ao Sr. Delegado de polícia da cidade de Altamira, solicitando a apreensão do produto tão logo chegasse ao porto daquela cidade, até que fôsse esclarecido a natureza da transação (RF, v. 8, p. 1.496, sic).

Continuando, Marinho indica que

[D]ecorrido tres dias, quando ------- já me encontrava em Belém, chegou o cidadão de alcunha "Maranhense", com o carregamento de castanha, que foi liberado pelo Sr. Suplente de Juiz, para venda à firma A. C. Maués, considerando que o comerciante ambulante portava um documento do responsável pelo posto Indígena Gorotine, na qual declarava "haverem os índios vendido, ao comerciante, duzentas caixas de castanha, num momento em que havia se ausentado do local de trabalho, recebendo os índios pagamentos diversos, desobrigando-o de qualquer responsabilidade". Todavia considerando que o produto indígena sòmente poderá ser negociado com a assistância de servidores do SPI, a questão foi levada a Justiça, através do Dr. Wilson 
Souza, Advogado desta Inspetoria que encaminhou o pedido do de apreensão ao Exmo. Sr. Dr. Juiz Federal dêste Estado, que o deferiu (RF, v. 8, p. 1.496-1.497, sic).

Diz Marinho que pretendia "com essa providência reaver o produto, que além de ter sido comprado indevidamente, pertencia a outra firma com quem a $2^{\mathrm{a}}$ Inspetoria regional mantém contrato e que antes do início do fabrico [colheita]", em continuação, indica o sistema de aviamento ${ }^{8}$ existente na bacia do Xingu, indicando que "abasteceu os postos indígenas da região com mercadorias e combustíveis, que seriam pagos com a produção dos mesmos [castanha] (RF, v. 8, p. 1.497, sic).

O documento reservado continua a relatar as idas e vindas relativas à apreensão, liberação e nova apreensão, e até roubo dos estoques da firma interessada na compra.

[O] Sr. Cel. Delegado da Polícia Federal colocou à disposição desta Regional, um Agente Federal, que posteriormente seguiu, juntamente com o Inspetor Meireles e o Dr. Wilson Souza, à cidade de Altamira, ocasião que procederam a apreensão do produto, tendo o mesmo ficado sob custódia da Prefeitura, no galpão do trapiche do porto da cidade de Vitória, naquele Município, até que a decisão Judicial fosse exarada. Chegando ao conhecimento do Inspetor Meireles, haverem outras irregularidades de ordem administrativas, ocorrendo nas regiões do Postos Indígenas, decidiu empreender uma viagem aos altos rios, levando em sua companhia o Agente Federal, antes porém, telegrafou à Séde da Inspetoria, solicitando a minha presença na cidade de Altamira, a fim de acompanhar o desenrolar dos acontecimentos. Desloquei-me de Belém levando em mão a resolução do Exmo. Sr. Dr. Juiz dos Feitos da Fazenda Federal, determinando fôsse o produto entregue ao SPI, cuja determinação, não foi considerada pelo Sr. Suplente de Juiz, voltando tudo ao estado de coisas (RF, v. 8, p. 1.497, sic).

\footnotetext{
${ }^{8}$ Sistema de aviamento corresponde a uma cadeia de fornecimento de bens a crédito, que produzia o endividamento do trabalhador antes da realização do trabalho contratado, deixando a pessoa em situação de vulnerabilidade. $\mathrm{O}$ endividamento prévio e contínuo do trabalhador - no caso, do indígena - com o contratante - comerciantes e SPI - deixa os povos indígenas e o órgão em situação difícil, fato que dá margem a diversos tipos de chantagens e irregularidades. Para uma discussão aprofundada sobre o aviamento e os efeitos sociais desse sistema, consultar: Márcia Motta (2005) e Roberto Santos (1980).
} 
As dificuldades só faziam crescer o conflito. Marinho apresenta então a versão que o transforma em vítima, apontando que "[d]urante os poucos dias que alí permanecí, sofrí coação da parte de elementos interessados em tumultuar a questão, forçando o meu retôrno à Belém" (RF, v. 8, p. 1.497, sic).

Marinho prossegue, apresentando-se como vítima de embaraços em Altamira e Belém, narrando que

[N]esse interregno, infâmias várias fôram assacadas a minha pessoa, que para melhor clareza, passo a relatar: a) - o Suplente de Juiz, Sr. João Horácio Monteiro, expediu citação dando o prazo de cinco dias para me apresentar naquele Juizado, a fim de responder pelo crime de ter mandado invadir o depósito da firma A. C. Maués, por dois individuos que de lá retiraram duzentas caixas de castanha e que o não comparecimento dentro do prazo fixado, consistiria na ordem de minha prisão. Os dois individuos são: Dr. Wilson Souza, Advogado da Inspetoria e o Agente Petra da Polícia Federal; b) - o proprietário da firma A. C. Maués, o Sr. Suplente e mais um cidadão de nome Evangelista, que se intitulou advogado da firma, quando ainda me encontrava na cidade de Altamira, desacataram-me e tentaram humilhar-me, ocasião que detrataram o SPI e ofenderam a todos seus servidores, indistintamente. Não resistindo, fui obrigado a reagir, o que mais acelerou os ânimos revoltados daquele que se sentiam prejudicados com a ação disciplinar imposta; c) quando perceberam que a violência não surtia o efeito desejado, apelaram para o subôrno. A primeira vítima foi o agente Petra da Polícia Federal e a segunda, o signatário da presente, fato ocorrido no mês de julho pretérito, nesta Capital. - Após haver decorrido tres meses e já tendo a Alta Instância proferido despacho dando ganho de causa ao Spi, outro ato arbitrário, a meu ver, foi cometido pelo rábula João Horácio Monteiro, que dizendo-se possuidor de ordem superior, fez prevalecer a sua autoridade, liberando a casta[nha] a favor da firma A. C. Maués, a revelia do Spi, que somente tomou conhecimento quando o produto já havia sido entregue a uma firma nesta praça. - Embora soubessemos do despacho favorável da Alta Instancia, nada podemos fazer, visto que dependiamos de recursos para locomoção de dois oficiais de justiça, determinado pelo Juiz, e de um funcionário desta Inspetoria à cidade de Altamira, onde procederiam o embarque do produto para Belém, o que não ocorreu pelo motivo exposto. Diante do dilema, ainda esbocei uma tentativa 
procurando impedir fôsse o produto transacionado. Dirigi-me ao Sr. Cel. Delegado da Polícia Federal, que em virtude do processo judicial estar na Instancia Superior, nada poude fazer, salvo se Exmo. Sr. Juiz solicitasse a apreensão através daquele Órgão. - Em virtude do advogado desta Inspetoria encontrar-se ausênte de Belém, dirigimo-nos ao Exmo. Sr. Dr. Juiz, que também negou o atendimento, salvo se a solicitação fôsse procedida através do Advogado do Serviço. - Não obstante havermos, aparentemente, perdido a questão, a Ação Judicial continua (RF, v. 8, p. 1.497-1.498, sic).

Lendo a defesa, percebe-se que "perder a cabeça", "invadir lugares" e "ameaçar pessoas" parecia ser a tônica corrente entre os agentes do SPI, pois os inqueridos alegam sempre agir com "indignação", "obrigados a reagir" nos diversos registros que produzem em sua defesa, em depoimentos ou documentos escritos de próprio punho às folhas do RF. Quanto à menção ao suborno, informada por Marinho, ele não diz dos resultados da oferta; não se sabe se foi uma tentativa de suborno, nem se o fruto do suborno foi recebido, pois há silêncio sobre o assunto. Cabe problematizar, interrogar se a propina proposta seria a forma dos opositores do SPI evitarem o conflito. Provavelmente, jamais saberemos, mas pelas atrocidades presentes no Relatório Figueiredo, temos indícios para, pelo menos, perquirir escrupulosamente o tema - aliás um dos motivos da Comissão de Inquérito.

As escusas finais de Marinho, em sua defesa, chegam a ser patéticas, pois apresenta como testemunhas pessoas que participaram das ações antes referidas: "Os testemunhos do Agente Federal Petra e do Dr. Wilson Souza, além dos Autor constantes do Processo que se encontra no Foro" (RF, v. 8, p. 1.499, sic), o que parece não oferecer credibilidade. Ele encerra o documento dizendo que "[n]o que se refere a minha atuação em ambos casos, desnecessário se faz qualquer comentário a respeito, deixando-o à apreciação e julgamento de Vossa Senhoria" (RF, v. 8, p. 1.499). E sugere: "Permita-me vos esclarecer da necessidade do comparecimento da Comissão de Inquérito, da qual Vossa Senhoria é Presidente". Finaliza em tom que parece-nos pouco respeitoso, como um desafio, afirmando que "maiores detalhes e provas poderão ser constatados [quando o procurador vier a Belém], quando também terei a 
oportunidade de pedir vistas do que recai sôbre a minha pessoa" (RF, v. 8, p. 1.499, sic).

Boanerges Fagundes de Oliveira, no termo de inquirição registrado no RF, produz acusação contra Marinho ao informar que "JOSE [Marinho] TELES FILHO Inspetor Regional Substituto da IR 2 vendeu Mogno no Pará" (RF, v. 8, p. 1574). Além de ter "alferido daí [da venda de madeira] vantagens de tal ordem que lhe proporcionou a compra de um VOLKS zero quilometro e a construção de uma casa, verdadeira mansão" (RF, v. 8 , p. 1.574 , sic).

$\mathrm{Na}$ inquirição de Francisco Furtado Soares de Meireles, chefe da $2^{\mathrm{a}}$ Inspetoria Regional, no período compreendido entre 1964 e 1967, o sertanista ao depor confirmou as informações oferecidas por José Marinho Teles Filho sobre a Ajudância do Xingu, a respeito da venda de castanhas do Gorotire e da retirada de madeira de Mãe Maria. Afirma que "denuncias de desonestidade de ire, digo, irregularidade tanto no caso da castanha como no caso de mogno; que supõe serem essas denuncias produto de enveja do Sr. QUEIROZ, estabelecido em MARABÁ" (RF, v. 8, p. 1.579 , sic).

Sobre o caso de Gorotire, Meireles depositou a "conta" nas costas das dissensões SPI versus Missões Religiosas, dizendo

que existem certas peculariedades desconcertantes entre certos "missionários" extrangeiros dentro e fora da area do SPI; que, por exemplo existe certas missões que usam cavar buracos a títulos dif, digo, deversos e não permitem que estranhos d ele se aproximem; que a exemplo disso no Pôsto GORORILE, digo, GOROTILE que o depoente reconhece haver missões com trabalhos elogiaveis, mas noutros não se nota aproveitamento entre os indigenas (RF, v. 8, p. 1.579 , sic).

Refutou ainda as denúncias de Boanerges, informando que

não considera JOSE [Marinho] TELES FILHO um homem rico sabendo apenas que possui um apartamento, comprado com produto da venda de uma casa que herdou em Manaus e com prestações decorrentes de economia sua, um pequeno terreno na PRIA DE MARUDA e um automóvel que adquiriu a prestação; que JOSÉ TELES FILHO aluga o apartamento de sua propriedade e reside em outro pelo qual paga um aluguel significante (RF, v. 8, p. 1.579 , sic). 
Cruzando os depoimentos, percebe-se que há sintonia e cumplicidade entre Marinho e Meireles, a qual pode ter sido alicerçada pelos anos de trabalho na 2a Inspetoria Regional, ou também pelo comprometimento de ambos nas situações descritas.

\section{Marinho e Meireles e os enlaces na Ajudância do Xingu}

José Marinho Teles Filho, após as denúncias, e a apuração das mesmas pela Comissão de Inquérito, terminou demitido, "a bem do serviço público", pela pena de Emílio Garrastazu Médici, presidente da República (1969-1974) nos anos de chumbo. O ato encontra-se divulgado pelo Jornal de Serviço, de 2 de abril de 1970. Ao que parece, Marinho não conseguiu se livrar das acusações feitas por Boanerges Fagundes de Oliveira e José Maria da Gama Malcher de "enriquecimento sem causa" [ilícito] (RF, v. 4, p. 841 e v. 8 , p. 1.574) e "envolvimento em negociatas de mogno e castanha-do-Pará", atividades de venda ilícita de mogno e em duplicidade de castanha-do-Pará pertencente aos Kayapó de Gorotire (RF, v. 4, p. 841 e v. 8, p. 1.574 e 1.578).

Quanto a Francisco Furtado Soares de Meireles foram imputadas 19 denúncias, enumeradas nas folhas 6.522 e 6.523 (RF, v. 28). Verifica-se aqui apenas as denúncias que dizem respeito à Ajudância do Xingu, a saber:

(7a) participação nos lucros dos trabalhos dos índios; $[\ldots]$

$\left(10^{a}\right)$ manipulação de verbas, adulterações e consertos de documentos em prestação de contas, irresponsabilidades no trato dos dinheiros; $[\ldots]$

$\left(12^{\mathrm{a}}\right)$ descontou promissória de sua emissão no Banco da Amazônia S/A avaliada por seringalistas de Altamira para financiamento dos índios Kayapós;

$\left(13^{a}\right)$ as castanhas do Posto Indígena Gorotire fôram vendidas duas vezes, ocasionando queixa a Justiça Federal, em Belém;

[...]

$\left(15^{\mathrm{a}}\right)$ contratou Wladirson O. Penna o corte de 2000 toras de mogno e outras madeiras de lei a CR $\$ 7.000$ por 
árvores abatida. A Inspetoria recebeu CR $\$ 2.800,000$ referente a madeira retirada (RF, v 28, p. 6527-6528).

Em sua defesa, diz o inquirido a respeito da $7^{a}$ denúncia que se trata de "pura infâmia", e afirma poder "invocar o testemunho de quantos me conhecem e sabem como procedo junto aos índios" (RF, v. 28, p. 6.533). Em seguida, refuta a $10^{a}$ denúncia, informando que "foi sempre necessário fazer esses extôrnos e consertos em recibos por pessôas ignorantes e pouco instruídos e modestos comerciantes do interior,

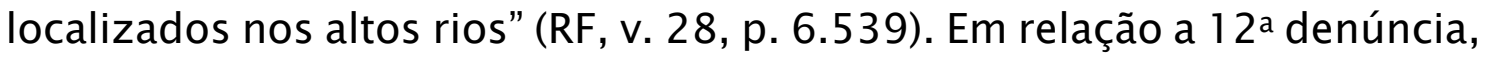
o inspetor Meireles informa que a negociação com 0 banco foi diretamente autorizada pelo chefe da Casa Militar da Presidência da República, gal. Amaury Kruel, providenciado por intermédio da rubrica Fundo de Assistência ao Seringueiro. A respeito da $13^{a}$ denúncia, o inquirido repete a história narrada por Marinho, de que a venda teria sido feita sem autorização do chefe do Porto Gorotire, pelos próprios Kayapó. Defendendo-se da $15^{a}$ denúncia, Meireles se reporta ao depoimento que ofereceu à Comissão, e informa que não contratou o senhor Wlardison $\mathrm{O}$. Penna, colocando-se à disposição para comprovar a "lisura na aplicação do adiantamento" e a "honestidade da transação" (RF, v. 28, p. 6.535).

$\mathrm{O}$ documento de defesa de Chico Meireles, como era conhecido o sertanista, deixa entrever relações entre o SPI e os militares, responsáveis pelo golpe de estado. O fato aparece mais explícito nas observações feitas sobre Meireles, no depoimento de Antonio Cotrim Sorares, outro importante sertanista da história recente do indigenismo no Brasil, a Rubens Valente, quando informa que "o SPI não tinha dinheiro e que o governador do Pará, [cel.] Jarbas Passarinho, ${ }^{9}$ ia financiar a expedição [aos Kayapó]" (2017, p. 14). A expedição a qual se refere Cotrim deveria se deslocar para os Kayapó que, nos anos 60 do século passado, "eram considerados terríveis pela população [de Altamira e adjacências]" e, segundo o próprio Meireles, eram "índios perigosos, [que] matavam os civilizados e aprisionavam as mulheres e, inclusive, várias moças foram raptadas tão cedo que acabaram por se integrar à vida da tribo."

\footnotetext{
${ }^{9}$ Foi nomeado governador do estado do Pará (1964-1966) após a deposição de Aurélio do Carmo pelo Golpe de 1964.
} 
Prosseguindo, diz o sertanista "[q]uando lá cheguei, eles tinham matado dezessete seringueiros" (VALENTE, 2017, p. 14)10.

Parte da defesa de Meireles consiste em desqualificar inicialmente Boanerges Fagundes de Oliveira e, na sequência José Maria da Gama Malcher. Faz acusações como se com eles ou por intermédio das acusações a terceiros as denúncias que recaiam sobre si se esvaíssem. $\mathrm{Na}$ verdade, as relações entre Gama Malcher e Francisco Meireles sempre foram tensas, e Meireles considerava que o desafeto era "mestre em 'químicas', isto é, em manipulação de verbas, adulteração e enxertos de documentos em prestações de contas" (VALENTE, 2017, p. 63).

Em face das denúncias presentes no Relatório Figueiredo, Meireles foi preso em outubro de 1976. Alguns dias após a prisão, a Comissão, presidida por Jader de Figueiredo Correia, voltou atrás na decisão, e, segundo Rubens Valente, foram considerados os atenuantes de ordem moral.

Meireles era descrito por seus apoiadores no SPI como um homem desligado das obrigações burocráticas, de poucas posses, cujas roupas e pertences caberiam numa única maleta. Sertanistas que o conheceram disseram que ele distribuía dinheiro a índios e caboclos e que usava seu próprio salario para atender a emergência dos postos indígenas $(2017, \text { p. } 63)^{11}$

As situações compreendidas pelo Relatório Figueiredo são de estarrecer, mas nosso propósito no trabalho é demonstrar como os descalabros, a omissão e a ausência do Estado brasileiro produziram uma política que na prática conduziu ao etnocídio e ao genocídio, efeitos sociais sobre os povos indígenas. Apesar de se reconhecer que o trabalho dos sertanistas tentasse/tente proteger os povos indígenas, eles trabalharam, também, no sentido de impedir que os povos indígenas atrapalhassem/atrapalhem os planos de desenvolvimento dos não indígenas (VALENTE, 2017). Propósitos que eram incompatíveis com o "bem viver" dos povos indígenas.

\footnotetext{
${ }^{10}$ Para melhor conhecer as disputas entre os moradores de Altamira e os Kayapó, consultar: Curt Nimuendaju (1982) e André Costa Nunes (2003). Destaco que, embora André Nunes alegue que o trabalho é ficção, a semelhança com as disputas altamirenses são realidades vividas ontem e hoje.

${ }^{11}$ As informações parecem ser confirmadas, a julgar pela concessão de pensão especial a Abigail Gomes, companheira de Meireles, via Lei no 7.129 de 10 de outubro de 1983.
} 


\section{Portas abertas em par ao genocídio}

O depoimento de Roque Laraia e Roberto DaMatta, na introdução de Índios e Castanheiros, dá a exata dimensão das consequências da malograda política indigenista para os povos indígenas. Refletem os antropólogos supramencionados que "o trabalho com populações tão duramente afetadas em sua demografia e valores provoca uma frustação no antropólogo" (1967, p. 21). Continuam os autores, alegando que "[d]iante de um punhado de índios que mal conseguem obter o alimento cotidiano" e passando pelo "rompimento de certas instituições e a impossibilidade física de manter certos grupos sociais em operação, todas as esferas da vida social ficam afetadas" (1967, p. 21 ).

Com pesar, Laraia e DaMatta constatam que

tudo parece indicar que em grupos tradicionalmente bem ajustados e de população reduzida, a depopulação afeta de modo drástico a padronização da conduta, ficando assim abertas tantas alternativas de ação quantas se tornarem necessárias para equilibrar o sistema social (1967, p. 21-22).

São os resultados das práticas "coloniais" impostas aos povos indígenas, no caso, os Gavião e os Surui, estudados por Laraia e DaMatta, que se considera etnocídio.

Torna-se necessário dizer que DaMatta trabalhou entre os Gavião no momento em que o Relatório Figueiredo estava sendo produzido. Informa-se também que a saga dos Gavião é bastante conhecida na área do rio Tocantins, pois seguidamente suas terras foram cortadas por inúmeros empreendimentos realizados no sul do Pará.

$\mathrm{Na}$ época em que DaMatta esteve entre os Gavião, eles haviam recém-chegado na Aldeia do 30, dizimados pelas correrias empreendidas e pelas epidemias. Eram 16 pessoas, dos quais 11 homens adultos e cinco mulheres. Foi o resultado da pacificação que removeu os Gavião de seu lugar de origem; o deslocamento foi desastroso.

As terras que hoje constituem a Reserva Indígena Mãe Maria foram asseguradas através do Decreto No 4503 de 28 de dezembro de 1943, assinado pelo interventor federal, cel. Joaquim Cardoso de Magalhães 
Barata. Após anos de luta, a reserva foi demarcada por intermédio do Decreto No. 93.148 de 20 de agosto de 1986, e registrada no SPU PA-04, livro 2, nas folhas 484 a 485, em 8 de setembro de 1986.

Consideramos que nem a demarcação, nem o decreto, proporcionaram tranquilidade aos Gavião, pois desde a instalação do Posto Indígena Mãe Maria em 1964, a partir de uma picada estreita que permitia o acesso à aldeia, a interlocução dos Gavião com os não indígenas tem sido intensa e dramática.

As terras em Mãe Maria abrigam os melhores castanhais da região do Tocantins, localizados no chamado Polígono da Castanha, área disputadíssima no sul do Pará, dado o seu significado políticoeconômico; nos anos 60 do século XX, os castanhais produziam cerca de 3.750 hectolitros de castanha-do-Pará por safra, ${ }^{12}$ cuja produção era totalmente entregue à Ajudância, fato não referido nas disputas anteriormente, apresentadas. 13

Voltando ao RF, não foi "descabido", do ponto de vista dos não indígenas, que as terras do antigo posto de atração tenham sido arrendadas a Wlardison O. Penna para retirada de 2.000 árvores ou 2.000 toras de madeira - caso fossem 2.000 toras, o número de árvores abatidas teria sido pelo menos o dobro, como afirmam os sertanistas e seus opositores. Evidentemente que mogno, ipê, cedro, jatobá e demais madeiras existentes no território gavião eram cobiçadas por muitos e geravam conflitos.

Uma das grandes lideranças parkatêjê, Topramre Krohokrenhum Jõpaipaire, afirma:

O trator passou derrubando a mata, tudinho... tudinho, dava pena! Era muito jaboti esmagado, madeira de mogno, tal de maracatiara, cedro... Tiraram Ipê, cedro... morreu muito bicho, madeira apodreceu, foi chuva, foi sol, nem fizeram nada. Nem Governo, nem Funai, nem no tempo do SPI. Ninguém fez nada, a gente não sabia que fazer, perdemos tudo. Todo mundo

\footnotetext{
${ }^{12}$ Nos anos 90 do século XX ainda se contavam em Mãe Maria pelo menos 12 colocações de castanha, que com as invasões e os cortes produzidos na Reserva, diminuíram em muito a produção. Mas, por safra, em 1997 produziam pelo menos 1.100 hectolitros de castanha-do-Pará.

${ }^{13} \mathrm{O}$ produto castanha-do-Pará, que era originalmente utilizado apenas como alimento, passou a possuir para os indígenas valor comercial em face da cobiça dos não indígenas e dos sucessivos arrendamento dos castanhais nativos. Foram alvo de muitas disputas até que os indígenas se apoderassem do sistema de produção e comercialização da castanha.
} 
"nos puseram na cabeça"[incutiram outras ideias], perdemos adoidado com reza de branco. Foi mogno, ipê e jatobá de muito, montes. Tinha madeira que nem tem mais, muito angelim pedra, marupá, caraopá. Não foi só madeira, foi jabuti, tatu, preguiça, veado, anta, muito animal que come fruta à noite. Estragou piquiá, bacuri, inajá, coco babaçu, açaí, bacaba, tudinho... Agora a gente já sabe que depois que chão preto passar não mata só bicho, mata gente, pois já matou castanhal, prejudicou as colocações, ${ }^{14}$ cortou no meio, ficou de duas metades. A produção de castanha não é mais igual, agora é bem pouco. De antes era muito. ${ }^{15}$

Quando se usa a metáfora "portas abertas em par ao genocídio", não se está exagerando. A categoria genocídio é aqui entendida como ações que produzem dizimação e acantonamentos dos povos indígenas - no caso do Brasil, no passado em aldeamentos, diretórios ou colônias indígenas e, mais tarde, em postos indígenas implantados pelo Serviço de Proteção aos Índios (SPI) e depois pela Fundação Nacional do Índio (FUNAI). Tais povos ficam impedidos de continuar a viver em seus territórios e de se reproduzirem socialmente da maneira como viviam antes da chegada dos invasores. A prática do genocídio foi produzida no passado colonial, mas ainda hoje se faz presente no cotidiano dos povos indígenas. Agora, sob vestes cada vez mais "refinadas", o Estado nega a autonomia requerida pelos protagonistas, e assim a história torna-se uma luta incessante.

No caso dos Gavião, a ida para a Aldeia do 30 os retira de seu habitat tradicional, por si só um elemento determinante para lacear as relações de reciprocidade e obrigações "diretamente ligadas à caça, coleta e agricultura" (LARAIA; DAMATTA, 1967, p. 102.). DaMatta continua a reflexão dizendo que "naquele ano [da chegada na Aldeia do 30] deixaram de se dedicar às suas tarefas agrícolas essenciais, como fazer uma roça que os pudesse sustentar nos períodos de penúria" (1967, p. 102). O grupo étnico não tinha a menor possibilidade de se sustentar no verão, quando a escassez de alimentos é drástica, restando apenas os

\footnotetext{
${ }^{14}$ Denominação regional dada à concentração de grande número de castanheiras em um castanhal nativo, como o dos Gavião.

${ }^{15}$ Entrevista concedida à Jane Felipe Beltrão, em 6 de maio de 1998, na Aldeia do 30, município de Bom Jesus do Tocantins (PA).
} 
tubérculos e as frutas; esporadicamente, a dieta poderia ser complementada pela caça.

O comprometimento social dos protagonistas indígenas não se restringe aos alimentos. Há desconforto causado pela depopulação, que os forçou a arranjos que feriam as regras de organização social e parentesco. Uma das regras que devem ter sido burladas foi a poligamia, substituída, supõe-se, pela poliandria, considerando o reduzido número de mulheres. Apesar de o assunto ser silenciado pelos membros do grupo, essa é uma dedução que nos parece lógica. A situação era de tal maneira drástica que DaMatta não acreditava que eles alcançassem êxito enquanto grupo étnico, e muito menos que crescessem a ponto de se constituírem hoje mais de 800 pessoas dentro da Reserva Indígena Mãe Maria.

O desastre da política indigenista pesou nas costas dos Parkatêjê, Kyikatêjê e Amikratêjê, antes conhecidos como Gavião.

Parece-nos adequado pensar sob o mesmo filtro em relação aos Kayapó, que ainda hoje, por conta da Usina Hidrelétrica de Belo Monte, lutam por gerenciar com autonomia e autodeterminação seu "bem viver".

A leitura atenta do Relatório Figueiredo nos faz compreender por que ele foi "desaparecido". Escondê-lo parece ter sido o álibi para evitar a comprovação do que as memórias e as histórias indígenas insistem em apontar: a essencialidade dos territórios étnicos e os efeitos sociais do esbulho ao qual os ditos territórios foram submetidos.

No presente, ainda padecemos com a valorização das fontes escritas - caso do Relatório Figueiredo, fato que ofusca e inferioriza a contundência dos depoimentos orais feitos pelos povos indígenas. Se a proposição se faz minimamente verdadeira, a "perda" do Relatório Figueiredo implica a tentativa de diminuir a intensidade e a eloquência da oralidade indígena sobre o genocídio. Oralidade que não esquece de registrar fatos e violações, os quais sem a devida compreensão da lógica nativa, podem ser - e na verdade, foram - silenciados por décadas.

É hora de dar valor aos testemunhos indígenas, e a partir deles demonstrar como o Estado praticou uma política pública de omissão que resultou em dizimação dos povos indígenas no Brasil, tão intensa quanto as limpezas étnicas praticadas em momentos de guerra. A pergunta que nos engasga e tortura é: limpeza étnica não é genocídio? Responde-se: 
é. Desvendar os nós que esconderam os fatos é dever ético e de ofício dos profissionais que se dedicam à história indígena.

\section{Referências documentais}

Acervo documental sobre os povos indígenas do Araguaia-Tocantins e do Xingu pertencente à Jane Felipe Beltrão.

BRASIL. Relatório Figueiredo: documento na íntegra. Brasília, 2013. Disponível em: <http://racismoambiental.net.br/2013/06/02/relatorio-figueiredo-documento-na-integra7-mil-paginas-pdf-pode-agora-ser-baixado/> . Acesso em 4 fev. 2015.

Comissão Nacional da Verdade (CNV). "Povos Indígenas e Ditadura Militar Subsídios à Comissão Nacional da Verdade 1946-1988”. In: Relatório parcial 01 de 30/11/2012, Brasília, 2012. Disponível em: $<$ https://idejust.files.wordpress.com/2012/12/povos-indc3adgenas-e-ditadura-militarrelatc3b3rio-parcial-30_11_2012.pdf>. Acesso em 10 fev. 2016.

DISPENSA de ponto na GB. Médici demite a bem do serviço público. Jornal de Serviço, Rio de Janeiro, n. 23.607, 2 abr. 1970. Brasil, p. 22. Disponível em: <http://memoria.bn.br/DocReader/Hotpage/HotpageBN.aspx?bib=089842_08\&pagfis= 4356\&url=http://memoria.bn.br/docreader\#> . Acesso em 25 maio 2018.

\section{Referências bibliográficas}

GOW, Peter. 'Me deixa em paz' Um relato etnográfico preliminar sobre o isolamento voluntários dos Mashco. Revista de Antropologia, São Paulo, v. 54, n. 1, p. 11-46, 2011. Disponível em: 〈http://www.revistas.usp.br/ra/issue/view/3199/showToc>. Acesso em: 27 dez. 2018.

GUIMARÃES, Elena. Relatório Figueiredo: entre tempos, narrativas e memórias. 2015. 204 f. Dissertação (Mestrado em Memória Social) - Programa de Pós-Graduação em Memória Social, Universidade Estadual do Rio de Janeiro - UERJ, Rio de Janeiro, [2015]. <http://www.memoriasocial.pro.br/documentos/Disserta\%C3\%A7\%C3\%B5es/Diss373. pdf $>$. Acesso em 6 mar. 2015.

LARAIA, Roque de Barros; DAMATTA, Roberto. Índios e castanheiros: a empresa extrativa e os índios do Médio Tocantins. São Paulo: Difel, 1967.

MOTTA, Márcia. Dicionário da terra. Rio de Janeiro: Civilização brasileira, 2005.

NIMUENDAJU, Curt. Textos indigenistas. São Paulo: Ed. Loyola, 1982. 
NUNES, André Costa. A Batalha do Riozinho do Anfrísio: uma história de índios, seringueiros e outros brasileiros. Belém: SECUT/FUMBEL, 2003.

SANTOS, Roberto. História Econômica da Amazônia 1800-1920. São Paulo: T.A. Queiroz, 1980.

SOUZA LIMA, Antônio Carlos de. Um grande cerco de paz: poder tutelar, indianidade e formação do Estado no Brasil. Petrópolis, Vozes, 1995.

VALENTE, Rubens. Os fuzis e as flechas: história de sangue e resistência indígena na ditadura. São Paulo: Cia. das Letras, 2017.

Recebido em: 02/06/2018 * Aprovado em: 17/10/2018 * Publicado em: 29/12/2018 